International Journal of Tropical Medicine 7 (3): 111-116, 2012

ISSN: $1816-3319$

C) Medwell Journals, 2012

\title{
Effects of a Type V Phosphodiesterase Inhibitor (Tadalafil) on Indomethacin-Induced Gastric Ulceration in Rats
}

\author{
${ }^{1}$ I. Ajiboye Kolawole and ${ }^{2} \mathrm{~S}$. Oluwole Francis \\ ${ }^{1}$ Department of Physiology, Benjamin S. Carson School of Medicine, \\ Babcock University, Ilishan Remo, Ogun State, Nigeria \\ ${ }^{2}$ Department of Physiology, College of Medicine, University of Ibadan, Ibadan, Nigeria
}

\begin{abstract}
Gastric ulcer is one of the most prevalent gastrointestinal disorders and still remains a major on-going health concern. Phosphodiesterase V inhibitors (PDE V) are drugs currently used in the treatment of patients with erectile dysfunction and pulmonary hypertension. They act by increasing blood flow to tissues in response to increase cGMP levels. They are also Nitric Oxide (NO) donors. NO is a potent vasodilator which increases blood flow in tissues where present thus preventing tissue damage. This study therefore examined the effects Tadalafil (TAD) on Indomethacin-induced gastric ulceration in rats. Three studies were directed at examining the effects of Tadalafil on gastric ulceration, ulcer dimensions and histological profile in indomethacin-induced rats. Male Wistar Albino rats weighing between 180-220 g were used. Each experimental group containing 6 rats were divided based on the following pre-treatments: Group I (Control)-saline $\left(8 \mathrm{~mL} \mathrm{~kg}^{-1}\right)$, Group II-IV were pre-treated with graded doses of Tadalafil $\left(2,5\right.$ and $10 \mathrm{mg} \mathrm{kg}^{-1}$ body weight, respectively), Group V (Reference)-Cimetidine $100 \mathrm{mg} \mathrm{kg}^{-1}$. Ulcer was induced by administration of indomethacin (40 mg kg${ }^{-1}$ p.o) 30 min following pre-treatments. Results showed that Tadalafil significantly reduced Indomethacin-induced gastric ulcers when compared with the control group $(\mathrm{p}<0.05)$ at high doses. The ulcer area, depth and width were significantly different between the control group and the Tadalafil $10 \mathrm{mg} \mathrm{kg}^{-1}$ BW group. Tadalafil had ulcer-reducing effects similar to that of the reference drug, cimetidine. Similar pattern of dose-dependent attenuation of ulcer severity was observed in the histological study. This study provides evidence that Tadalafil possesses significant anti-gastric ulcer effects as it dose-dependently reduced gastric ulcers induced by Indomethacin in rats.
\end{abstract}

Key words: Tadalafil, gastric ulcer, PDE V inhibitors, ulcer, ulcer nitric oxide, cGMP

\section{INTRODUCTION}

Peptic ulcers usually result from an imbalance between aggressive forces and factors responsible for maintaining the defence of the gastric mucosa. They are usually characterized by a break in the mucosa of the stomach (gastric ulcer) or duodenum (duodenal ulcer). Phosphodiesterase (PDE) V inhibitors are drugs currently used to treat erectile dysfunction and pulmonary hypertension. This group of drugs works by increasing the regional blood flow in response to increased cyclic Guanosine Monophosphate (cGMP) synthesis. Decrease mucosal blood flow is a major factor underlying gastric mucosa damage (Whittle, 1977). PDE V inhibitors have been shown to promote an increase in cGMP concentrations in the GIT which in turn promotes the endogenous synthesis of NO (Santos et al., 2005) have beneficial anti-inflammatory effects of Sildenafil on bowel disease by enhancing cGMP synthesis (Khoshakhlaghet al., 2007) and ameliorate ethanolinduced gastric haemorrhagic damage (Medeiros et al., 2008). Since, PDE V inhibitors are nitric oxide donors and potent vasodilators which increase blood flow in tissues where present and thus preventing tissue damage, this study therefore examined the effects Tadalafil on indomethacin-induced gastric ulceration in rats.

\section{MATERIALS AND METHODS}

Animals: Male Wistar Albino rats weighing between $180-220 \mathrm{~g}$ were used for the study. They were procured from the animal house of the Physiology Department, University of Ibadan, Ibadan. The animals were fed with standard rat and mice pellets (Ladokun feeds, Ibadan) and

Corresponding Author: I. Ajiboye Kolawole, Department of Physiology, Benjamin S. Carson School of Medicine, Babcock University, Ilishan Remo, Ogun State, Nigeria 
given free access to water. Animals were divided according to the following experimental groups: Group I (Control)-saline, $8 \mathrm{~mL} \mathrm{~kg}{ }^{-1}$, Group II; Tadalafil $2 \mathrm{mg} \mathrm{kg}^{-1}$ B.W., Group III; Tadalafil $5 \mathrm{mg} \mathrm{kg}^{-1}$ B.W., Group IV; Tadalafil $10 \mathrm{mg} \mathrm{kg}^{-1}$ B.W., Group V (Reference); Cimetidine $100 \mathrm{mg} \mathrm{kg}^{-1}$ B.W. Studies carried out are:

Study 1: Effect of PDE V inhibitor (Tadalafil) on indomethacin-induced gastric ulceration.

Study 2: Determination of ulcer dimensions (area, depth and width).

Study 3: Histological profile of gastric mucosa.

Chemicals: Chemicals were purchased from Sigma Aldrich chemicals, Germany. Chemicals include Indomethacin, Cimetidine and Tadalafil (Evans Pharmaceutical).

\section{Experimental procedures}

Ulcer Induction: Indomethacin-induced ulceration model was adapted for this study (Wallace et al., 2000). Animals were fasted for $24 \mathrm{~h}$ prior to experimentation but had free access to water. The control group received Indomethacin (40 mg kg-1 bw, p.o). All other groups received Indomethacin ( $40 \mathrm{mg} \mathrm{kg}^{-1}$ bw, p.o) 30 min after receiving their respective pre-treatments. All animals were sacrificed $4 \mathrm{~h}$ later with ether overdose; the stomachs were removed and assessed for ulcer lesions (Elegbe, 1978).

Determination of ulcer scores: This is based on a modified method of Alphin and Ward (1967). Ulcers were independently assessed and scored by two observers using the following criteria: normal stomach (0), punctuate/pin-point ulcer $(0.5)$, two or more small haemorrhagic ulcers (1), ulcers $>2 \mathrm{~mm}$ (2).

Index of ulceration: Paul's Index was used as ulcer index (Martin-Aragon et al., 1994). This index is expressed as:

$$
\frac{\mathrm{MxN}}{100}
$$

Where:

$\mathrm{M}=$ Mean number of ulcers per rat in the group

$\mathrm{N}=$ Percentage of rats with ulcer in the group

Percentage inhibition:

$$
\text { Inhibition }(\%)=\left[I_{c}-I_{t} / I_{c}\right] \times 100
$$

Where:

$I_{c}=$ Ulcer index for control group

$I_{t}=$ Ulcer index for the treated group

Determination of ulcer dimensions (area, depth and width): Ulcer dimension (area, depth and width) determinations were determined using Micrometric Software, Motic 2000. The stomach samples were flattened and carefully sandwiched between two layers of transparent plastic folders and then scanned with the Motic 2000 image software.

Histological assessment: Histological profiling of the ulcerated gastric mucosa was based on the method described by Sheehan and Hrapchak (1987) using Periodic Acid Schiff staining (PAS). Stomachs fixed with 10\% formalin and embedded in paraffin were sectioned at $5 \mu \mathrm{m}$ in an automated microtome. The gastric tissue integrity (mucosa-submucosa) was assessed for damage.

Statistical analysis: Data were expressed as Mean \pm SEM. Statistical difference between test groups and control group was calculated using the Student's t-test. The $\mathrm{p}<0.05$ was considered as significant.

\section{RESULTS AND DISCUSSION}

Peptic ulcer represents a leading concern among gastrointestinal tract disorders and even though there are a variety of treatment protocols for the condition, each with its varying degree of success and side effects, none has been able to completely cure the condition. Microcirculation around the gastrum has been shown to have significant ameliorative capabilities on ulcer formation and healing (Hirose et al., 1991). One factor that contributes to the effect of microcirculation on ulcer is Nitric Oxide (NO). The NO/cGMP pathway has been implicated in the pathogenesis of ulcers by several authors (Duffin et al., 2008; Santos et al., 2005). PDE V enzymes (which are cGMP-specific) are responsible for the degradation of cGMP in the body tissues. Thus, PDE $\mathrm{V}$ inhibitors will sustain cGMP levels in tissues, an action believed to be mediated in part by NO through vasodilatation and increased blood flow. Originally used as cardioprotective drugs, PDE V inhibitors are now commonly used in the treatment of patients with erectile dysfunction. Coming from the background that agents that improve blood flow in tissues will mitigate ulcer damage, the current study therefore examined the effect of a known type 5 phosphodiesterase, tadalafil, on indomethacin-induced gastric ulcerations in rats. 
The result of the study showed that indomethacin administration resulted in extensive haemorrhagic damage to the gastric mucosa, especially in the control group (Fig. 1). Tadalafil had a dose-dependent reduction in ulcer score among the treated groups. There was a significant difference between the index of ulceration for the control group and that of the highest dose of tadalafil and between that of the control group and the cimetidine group (Table 1).

Table 1 shows a dose-dependent reduction in the ulcer score among the treated groups. There is a significant difference between the ulceration index for the control group and the tadalafil $\left(10 \mathrm{mg} \mathrm{kg}^{-1}\right)$ group $(\mathrm{p}<0.05)$ and also between the control group and the Cimetidine $\left(100 \mathrm{mg} \mathrm{kg}^{-1}\right)$ group $(\mathrm{p}<0.01)$. These results buttress previous observations that NO-releasing agents confer a significant degree of protection on the gastric mucosa against experimental NSAID-induced damage (Elliott et al., 1995; Wallace and Del, 2003). Furthermore, the ulcer dimensions were significantly reduced in the highest dose of Tadalafil $\left(10 \mathrm{mg} \mathrm{kg}^{-1} \mathrm{BW} ; \mathrm{p}<0.05\right)$ when compared with the control (Table 2) which is similar to results from other PDE inhibitors' effect on gastric tissue (Nakamura et al., 2003; Saud et al., 2005). Table 2 shows the effect of graded doses of Tadalafil (TAD) on ulcer dimensions (area, width and depth). This result corresponds with the pattern of index of ulceration. Ulcer area, width and depth were significantly reduced in the
$\mathrm{TAD} 10 \mathrm{mg} \mathrm{kg}^{-1}$ group (area $=\mathrm{p}<0.05$, width and depth $=\mathrm{p}<0.01)$ and in the Cimetidine $100 \mathrm{mg} \mathrm{kg}^{-1}$ group $(\mathrm{p}<0.01)$ when both were compared with the control group. TAD $5 \mathrm{mg} \mathrm{kg}^{-1}$ also showed a significantly lesser ulcer depth $(\mathrm{p}<0.01)$.

The actions of NSAIDs on the gastric epithelium may involve several mechanisms, most NSAIDs, particularly those of acidic nature can directly kill or denature epithelial cells leading to cell death (necrosis) and epithelial exfoliation. Thus, histological assessment of the stomach tissues showed a varying degree of mucosa damage as observed in previous studies (Karakaya et al., 2009). On the whole, there is a pattern of dose-dependent attenuation of NSAID-induced

Table 1: Mean ulcer score, ulcer index and percentage inhibition

\begin{tabular}{|c|c|c|c|}
\hline Treatments & Mean ulcer score & Paul's index & Inhibition (\%) \\
\hline Control & $12.50 \pm 4.17$ & 12.50 & - \\
\hline TAD $2 \mathrm{mg} \mathrm{kg}^{-1}$ & $9.67 \pm 0.90$ & 9.67 & 29.27 \\
\hline TAD $5 \mathrm{mg} \mathrm{kg}^{-1}$ & $7.17 \pm 2.64$ & 7.17 & 42.64 \\
\hline TAD $10 \mathrm{mg} \mathrm{kg}^{-1}$ & $4.58 \pm 1.51^{*}$ & 3.82 & 69.44 \\
\hline Cimetidine $100 \mathrm{mg} \mathrm{kg}^{-1}$ & $1.33 \pm 0.63^{* *}$ & 0.89 & 92.88 \\
\hline
\end{tabular}

Table 2: Ulcer area, width and depth

\begin{tabular}{|c|c|c|c|}
\hline Treatments & Area $\left(\mu m^{2}\right)$ & Width $(\mu \mathrm{m})$ & Depth $(\mu \mathrm{m})$ \\
\hline Control & 298 & 61. & 399 \\
\hline TAD $2 \mathrm{mg} \mathrm{kg}^{-1}$ & $245.01 \pm 3.98$ & $55.47 \pm 3.00$ & $3848.05 \pm 312$ \\
\hline TAD $5 \mathrm{mg} \mathrm{kg}^{-1}$ & $192.67 \pm 1.65$ & $49.19 \pm 3.21$ & $519.74 \pm 7.22^{* *}$ \\
\hline TAD $10 \mathrm{mg} \mathrm{kg}^{-1}$ & $132.67 \pm 1.21^{*}$ & $40.82 \pm 2.14^{* *}$ & $428.87 \pm 4.66^{* *}$ \\
\hline Cimetidine $100 \mathrm{mg} \mathrm{kg}^{-1}$ & $113.04 \pm 1.28^{* *}$ & $37.68 \pm 1.62^{* *}$ & $22.95 \pm 1.60^{* *}$ \\
\hline
\end{tabular}

Data expressed as Mean \pm SEM; $\mathrm{n}=6$, *Significant at $\mathrm{p}<0.05$ when compared with control; **tsignificant at $\mathrm{p}<0.01$ when compared with control

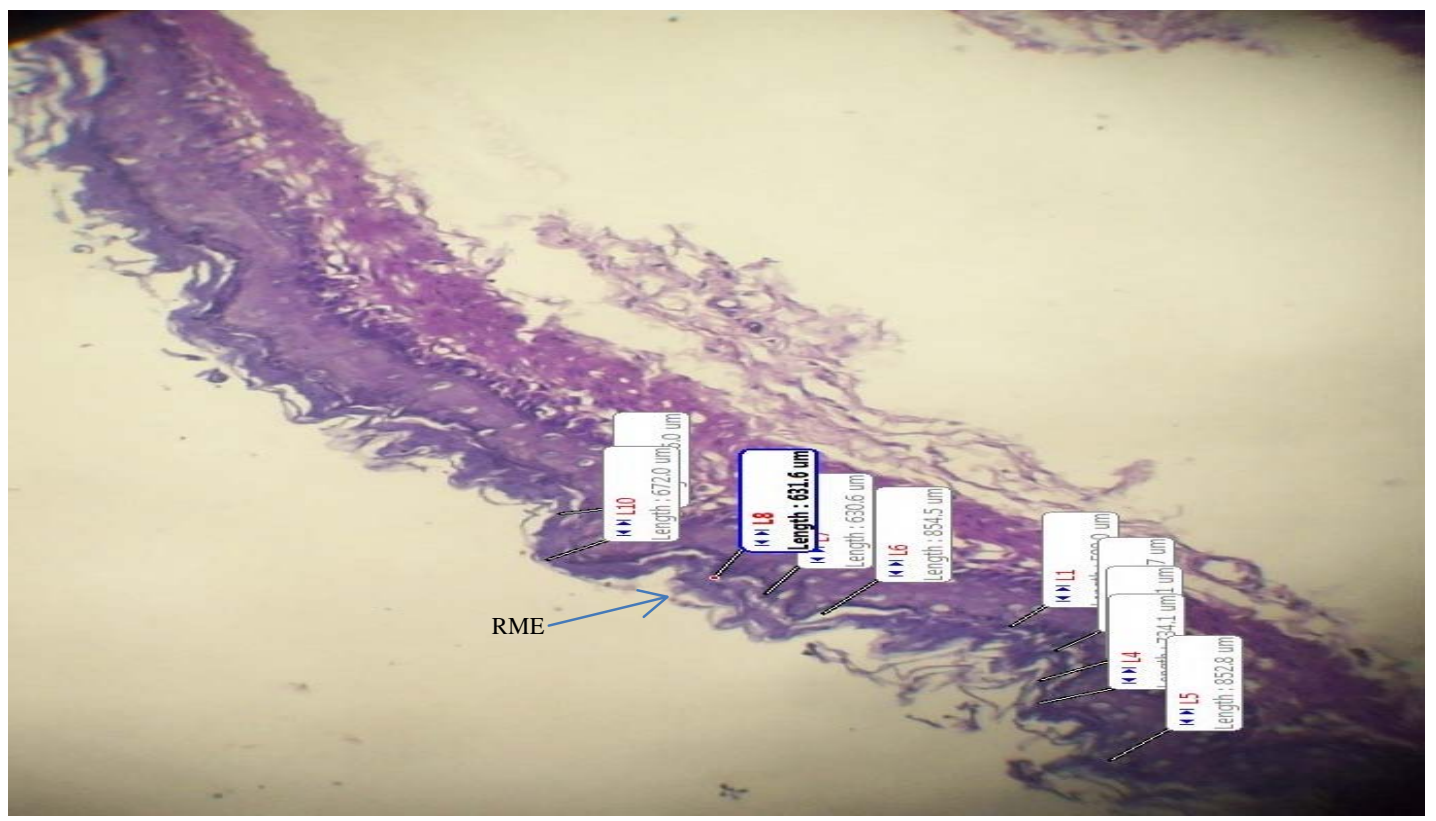

Fig. 1: Ulcer lesion in control animals complete mucosal and sub-mucosal exfoliation with reduced width of the muscularis externa (x40). RME: Reduced Muscularis Externa (Rectangular white markings are labels for the measurements of the ulcer depth) 
ulcer damage with the extensive mucosa damage observed in the low dose ( $2 \mathrm{mg} \mathrm{kg}^{-1}$ BW) (Fig. 2) not observed in the higher doses of 5 and $10 \mathrm{mg} \mathrm{kg}^{-1} \mathrm{BW}$
(Fig. 3 and 4). While the ulcerated area remains extensive in the TAD $5 \mathrm{mg} \mathrm{kg}^{-1} \mathrm{BW}$ group, the ulcer depth had been significantly reduced by Tadalafil thus pointing to

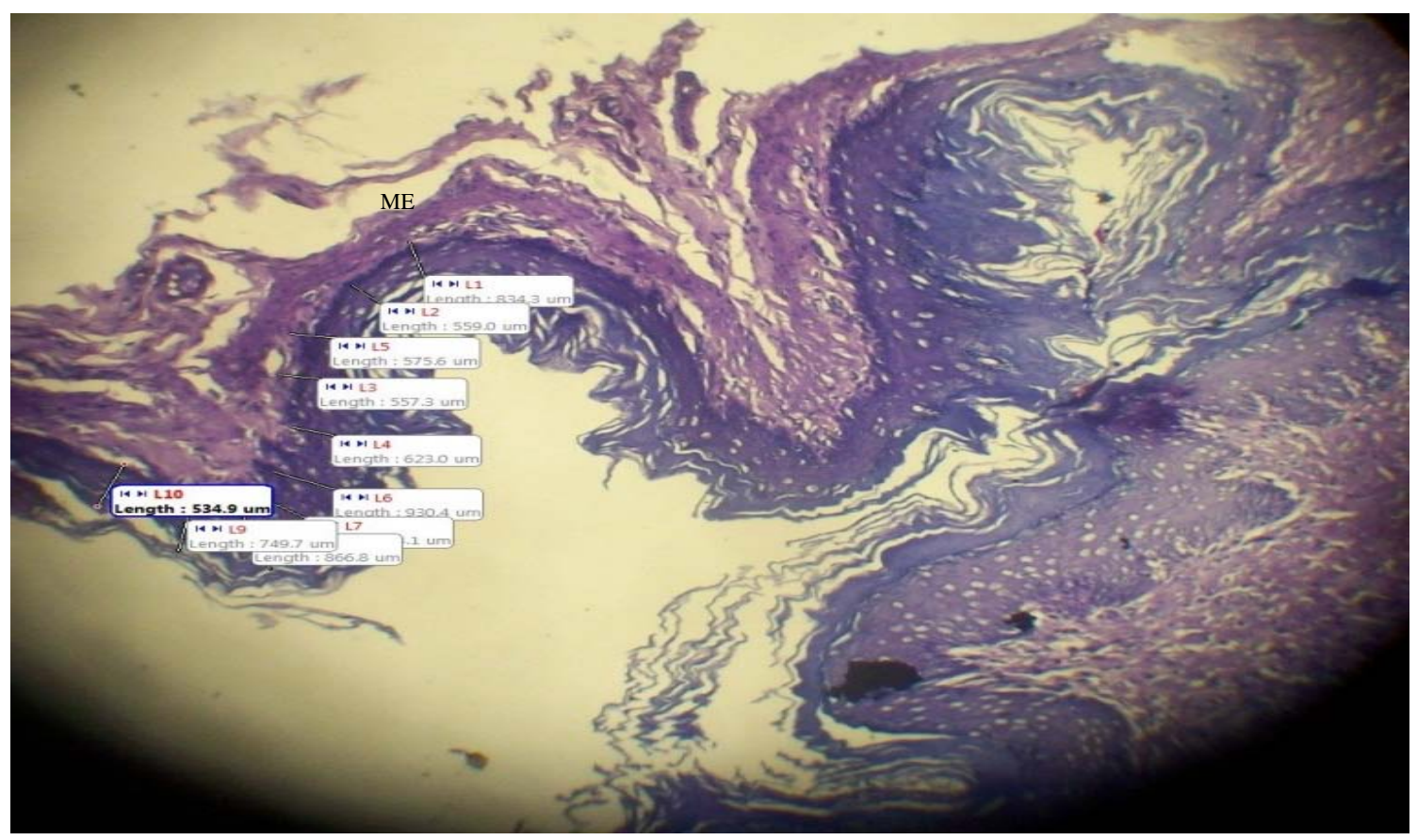

Fig. 2: Ulcer lesion in $\mathrm{TAD} 2 \mathrm{mg} \mathrm{kg}^{-1}$ animals. Complete mucosal and sub-mucosal exfoliation (x40). ME: Mucosal Exfoliation. Rectangular white markings are labels for the measurements of the ulcer depth

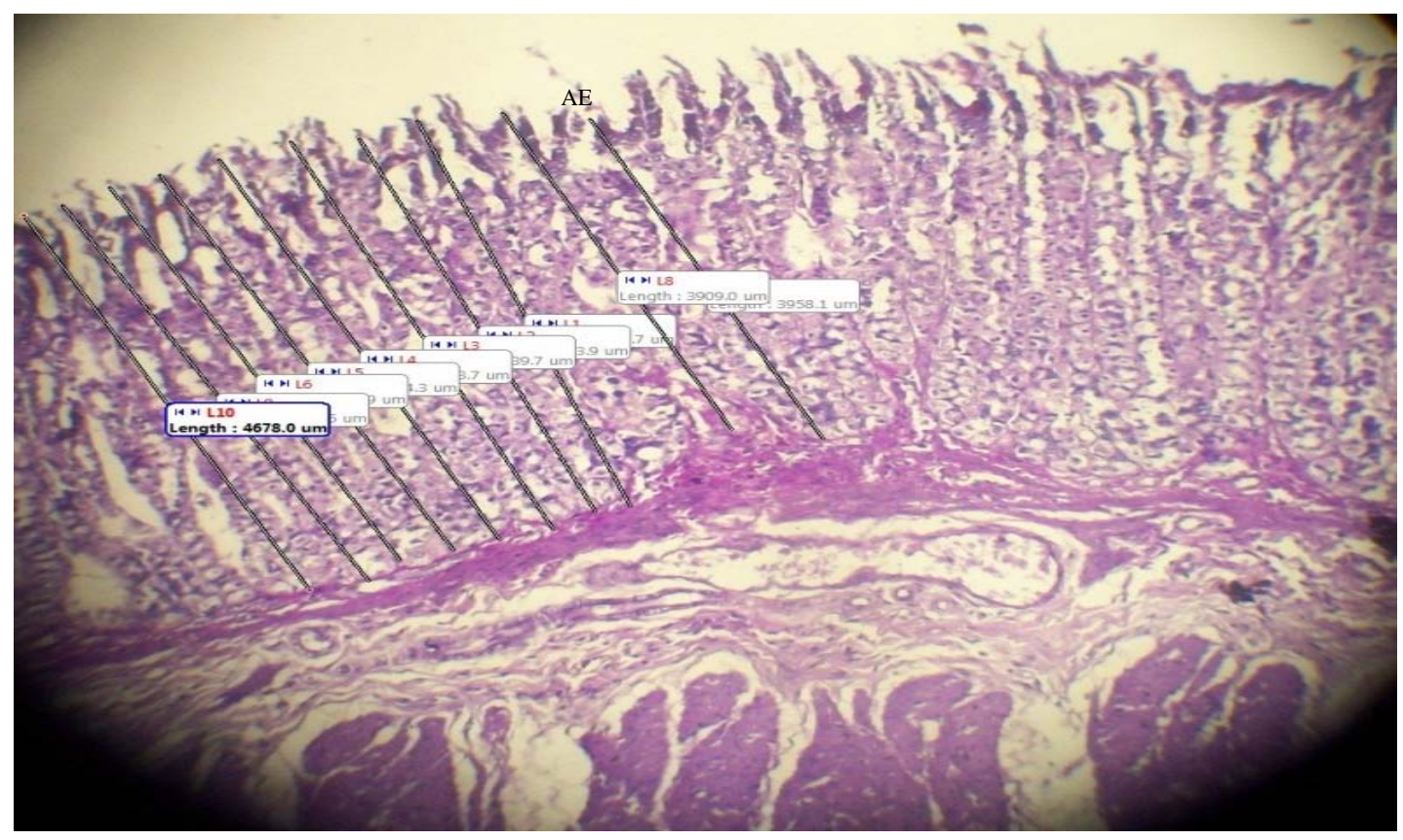

Fig. 3: Ulcer lesion in $\mathrm{TAD} 5 \mathrm{mg} \mathrm{kg}^{-1}$ animals. Slight apical glandular erosions with fairly intact sub-mucosa (x40). AE: Apical Erosions 


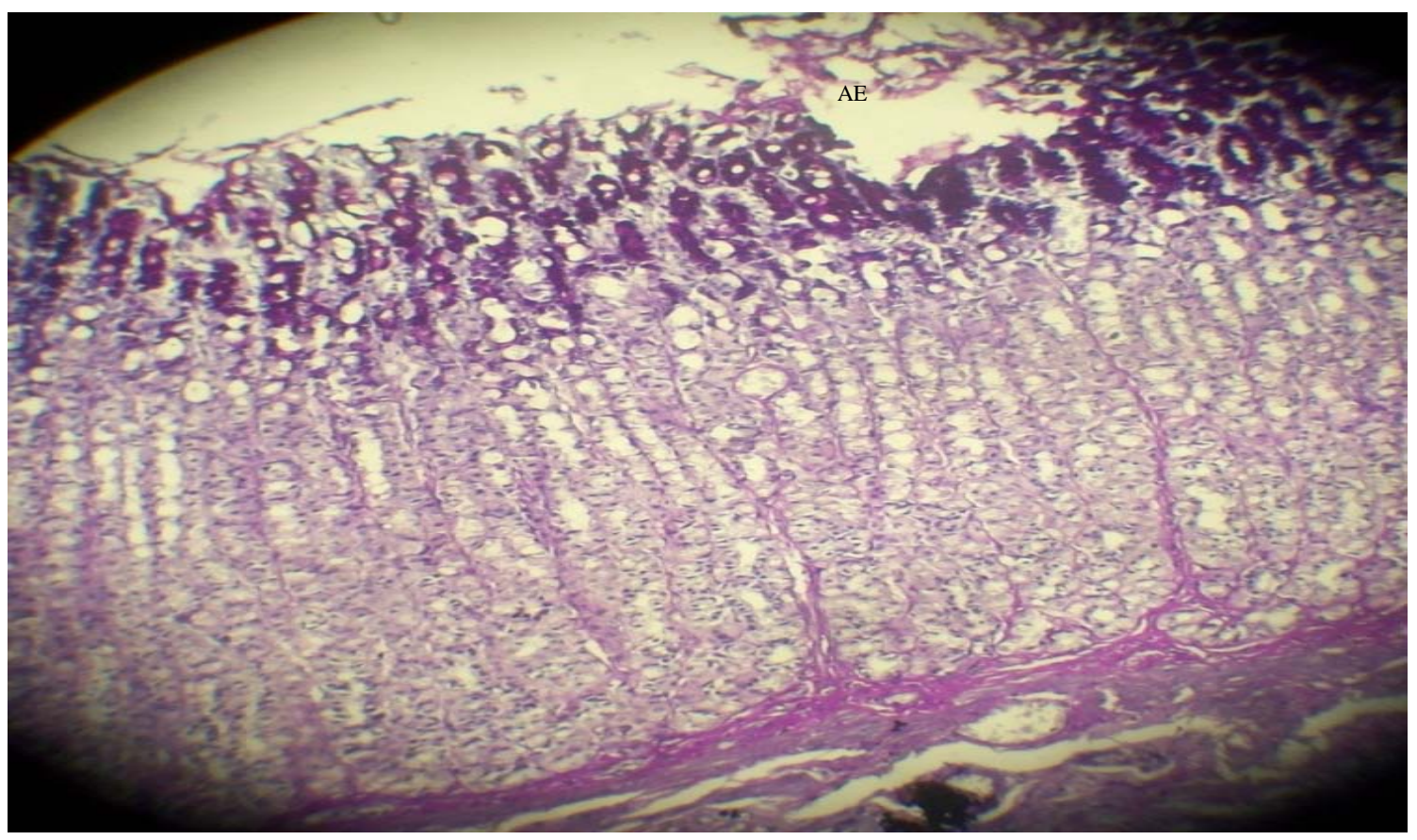

Fig. 4: Ulcer lesion in TAD $10 \mathrm{mg} \mathrm{kg}^{-1}$ animals. Normal glands with some Apical Erosion (AE) $\mathrm{x} 40$

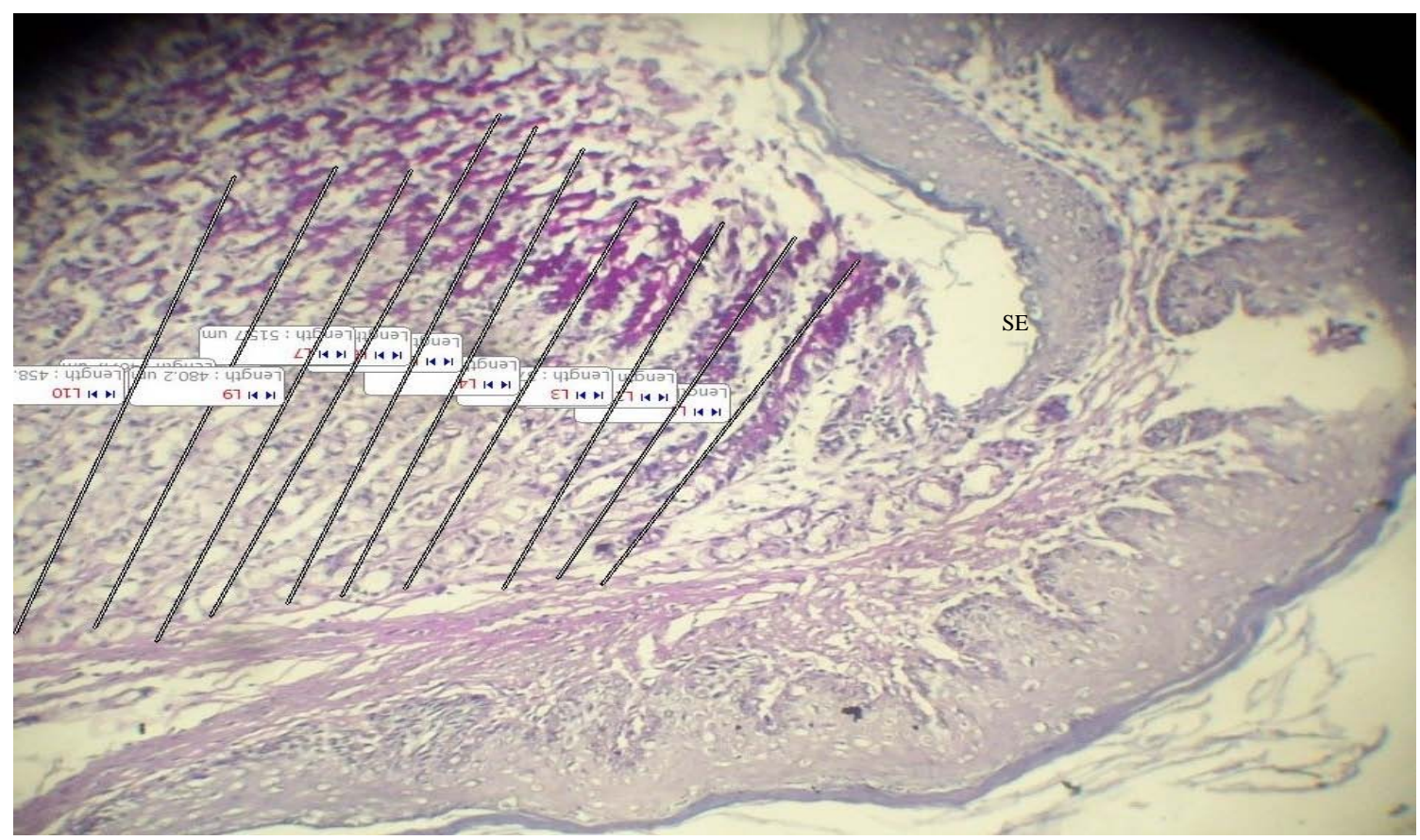

Fig. 5: Ulcer lesion in Cimetidine $100 \mathrm{mg} \mathrm{kg}^{-1}$ animals. Normal glands with few Sloughed Epithelium (SE) $\mathrm{x} 40$

a deeply lying/acting protective mechanism (Table 2). The cyto-protective effect of Tadalafil may not be unrelated to those conferred by the NO/cGMP pathway since, it is a NO donor although, this remains a speculation. It has been reported that $\mathrm{NO}$ and by extension its donors (such as Tadalafil) may protect 
against NSAID-induced damage by promotion of prostaglandin synthesis (Khattab et al., 2001). Further studies to confirm full mechanisms involved are still on-going.

Histology showed a dose-dependent attenuation of ulcer severity in the treated groups when compared with control. Histopathological examination showed that Indomethacin provoked deep alteration of glandular epithelium and a loss of histological structures that extended into the muscularis externa (not observed in the other treated groups). The Cimetidine $100 \mathrm{mg} \mathrm{kg}^{-1}$ group showed highest resistance to ulcer formation with some animals still having a fairly intact glandular epithelium (mucosa) (Fig. 5).

\section{CONCLUSION}

This study provides evidence that Tadalafil possesses significant anti-gastric ulcer effects as it dose-dependently reduced gastric ulcers induced by Indomethacin in rats. From these findings, patients treated with Tadalafil will benefit from the additional gastro-protective advantages this group of drugs may likely possess.

\section{REFERENCES}

Alphin, R.S. and J.W. Ward, 1967. Actions of hexopyrronium bromide on gastric secretion in dogs and on gastric secretion and ulceration in rats. Arch. Int. Pharmacodyn. Ther., 168: 82-100.

Duffin, R., C.A. Shaw and A.G. Rossi, 2008. Sildenafil reduces alcohol-induced gastric damage: Just say NO. Br. J. Pharmacol., 153: 623-624.

Elegbe, R.A., 1978. Comparative studies on starvation and indomethacin-induced ulcerations in albino rats. Biochem. Expt. Biol., 2: 159-166.

Elliott, S.N., W. McKnight, G. Cirino and J.L. Wallace, 1995. A nitric oxide-releasing nonsteroidal antiinflammatory drug accelerates gastric ulcer healing in rats. Gastroenterology, 109: 524-530.

Hirose, H., K. Takeuchi and S. Okabe, 1991. Effect of indomethacin on gastric mucosal blood flow around acetic acid-induced gastric ulcers in rats. Gastroenterology, 100: 1259-1265.

Karakaya, K., V. Hanci, S. Bektas, M. Can and H.B. Ucan et al., 2009. Mitigation of indomethacininduced gastric mucosal lesions by a potent specific type 5 phosphodiesterase inhibitor. World J. Gastroenterol., 15: 5091-5096.
Khattab, M.M., M.Z. Gad and D. Abdallah, 2001. Protective role of nitric oxide in indomethacininduced gastric ulceration by a mechanism independent of gastric acid secretion. Pharm. Res., 43: 463-467.

Khoshakhlagh, P., M. Bahrololoumi-Shapourabadi, A. Mohammadirad, L. Ashtaral-Nakhai, B. Minaie and M. Abdollahi, 2007. Beneficial effect of phosphodiesterase-5 inhibitor in experimental inflammatory bowel disease: Molecular evidence for involvement of oxidative stress. Toxicol. Mech. Methods, 17: 281-288.

Martin-Aragon, S., J. Benedi and A. Villar, 1994. Studies on the antiinflammatory and antiulcerogenic activities of Tuberaria lignose extracts in experimental animals. J. Pharmacol. Biol., 32: 27-32.

Medeiros, J.V., G.G. Gadelha, S.J. Lima, J.A. Garcia and P.M. Soares et al., 2008. Role of the $\mathrm{NO} / \mathrm{cGMP} / \mathrm{K}$ (ATP) pathway in the protective effects of sildenafil against ethanol-induced gastric damage in rats. Br. J. Pharmacol., 53: 721-727.

Nakamura, C., M. Otaka, M. Odashima and S. Watanabe, 2003. Rolipram, a specific type IV phosphodiesterase inhibitor, ameliorates indomethacin-induced gastric mucosal injury in rats. Pathophysiology, 62: 449-454.

Santos, C.L., M.H. Souza, A.S. Gomes, H.P. Lemos, A.A. Santos, F.Q. Cunha and J.L. Wallace, 2005. Sildenafil prevents indomethacin-induced gastropathy in rats: Role of leukocyte adherence and gastric blood flow. Br. J. Pharmacol., 146: 481-486.

Saud, B., J. Nandi, G. Ong, S. Finocchiaro and R.A. Levine, 2005. Inhibition of TNF- $\alpha$ improves indomethacin-induced enteropathy in rats by modulating iNOS expression. Digestive Dis. Sci. 50: $1677-1683$.

Sheehan, D.C. and B.B. Hrapchak, 1987. Theory and Practice of Histotechnology. 2nd Edn., Battelle Press, Columbus, OH., USA., ISBN: 9781574770674 , Pages: 481.

Wallace, J.L. and P.S. Del, 2003. The therapeutic potential of NO-NSAIDs. Fundam. Clin. Pharmacol., 17: 11-20.

Wallace, J.L., W. McKnight, B.K. Reuter and N. Vergnolle, 2000. NSAID-induced gastric damage in rats: Requirement for inhibition of both cyclooxygenase 1 and 2. Gastroenterology, 119: 706-714.

Whittle, B.J., 1977. Mechanisms underlying gastric mucosal damage induced by indomethacin and bilesalts and the actions of prostaglandins. Br. J. Pharmacol., 60: 455-460. 